Archive for

Organic Chemistry

Arkivoc 2018, part v, 1-10

\title{
Microwave-assisted solid-phase synthesis of nicotinyl hydrazones for use in radiochemistry of technetium-99m
}

\author{
Vania Teixeira, ${ }^{\mathrm{a}, \mathrm{b}}$ Pablo Cabral, ${ }^{\mathrm{a}}$ and Williams Porcal*b \\ a Laboratorio de Radiofarmacia, Centro de Investigaciones Nucleares, Mataojo 2055, Facultad de Ciencias, \\ Universidad de la República, 11400 Montevideo, Uruguay \\ ${ }^{b}$ Departamento de Química Orgánica, Av. General Flores 2124, Facultad de Química, \\ Universidad de la República, 11800 Montevideo, Uruguay
}

Email: wporcal@gmail.com

\section{Abstract}

We report a new method for efficient and rapid synthesis of HYNIC-hydrazone derivatives using microwaveassisted solid-phase. In comparison to the conventional heating procedure, microwave irradiation considerably accelerated the formation of HYNIC analogues. The synthesis time and efforts are significantly reduced in the present method, without side product formation. We proved that the HYNIC-hydrazone clustering can be directly labeled with technetium without exposing the free hydrazine group. Therefore, this

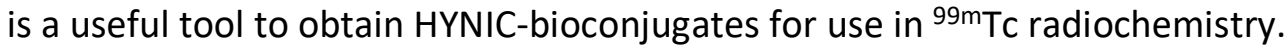
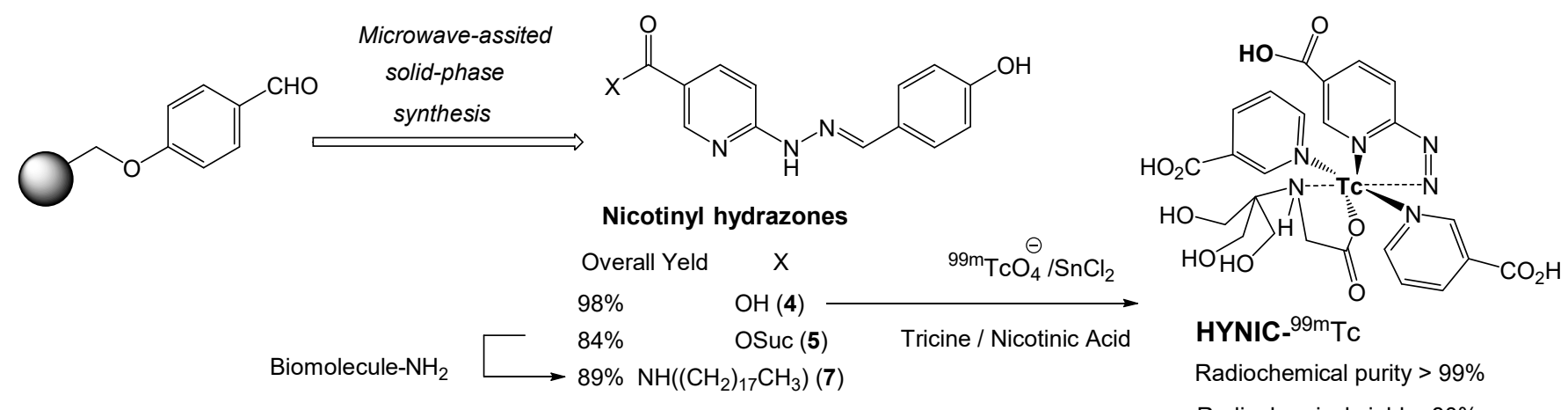

HYNIC- ${ }^{99 m}$ TC

Radiochemical purity $>99 \%$ Radiochemical yield $>80 \%$

Keywords: Microwave, solid-phase, HYNIC, hydrazone, chelation, technetium-99m 
One of the most useful isotopes in nuclear medicine is the metastable ${ }^{99 \mathrm{~m} T c}{ }^{1}{ }^{1}$ Technetium chemistry is based on the formation of complexes in which the metal acts as an electron acceptor from atoms or functional

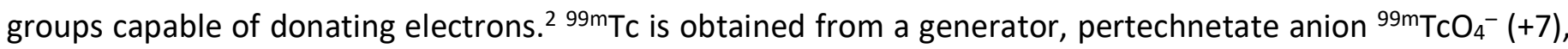
which must be reduced to a lower oxidation state with high chemical reactivity to be incorporated by a chelating agent. Once reduced to lower oxidation states, ${ }^{99 \mathrm{mT}} \mathrm{Tc}$ is capable of binding to a large number of organic and inorganic molecules in the form of coordination complexes. Among the different strategies, one of the most used is derivatization with bifunctional chelating agents.

The 6-hydrazinonicotinyl group, known as HYNIC, a pyridine derivative, is widely used as a bifunctional

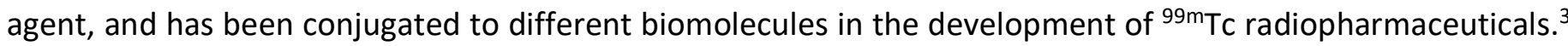
HYNIC generally is conjugated to biomolecules by forming an amide bond through the reaction between a HYNIC succinimidyl ester (Suc-HYNIC) and an amine group present in the biomolecule (Scheme 1). Several studies have proposed that the coordination between HYNIC and ${ }^{99 \mathrm{~m}} \mathrm{Tc}$ can occur through the $\mathrm{N}$ atom of the pyridine ring and / or the $\mathrm{N}$ atom of the hydrazine group, and requires the use of a coligand (e.g. tricine and/or nicotinic acid) to complete the coordination sphere around the metal. The free hydrazino group present in HYNIC derivatives or HYNIC-bioconjugates has a high susceptibility to oxidation reactions by light. Similarly, the high nucleophilic free hydrazino group could react with electrophilic molecules. Since conjugation reactions occur with a molar excess of HYNIC and the reagent hydrazino group could be in the free state in aqueous solution, it is likely that the activated ester also reacts with the highly nucleophilic hydrazino group, leading to HYNIC polymerization reactions. These unwanted reactions could lower the purity and stability of the HYNIC-biomolecule complex during the derivatization process.

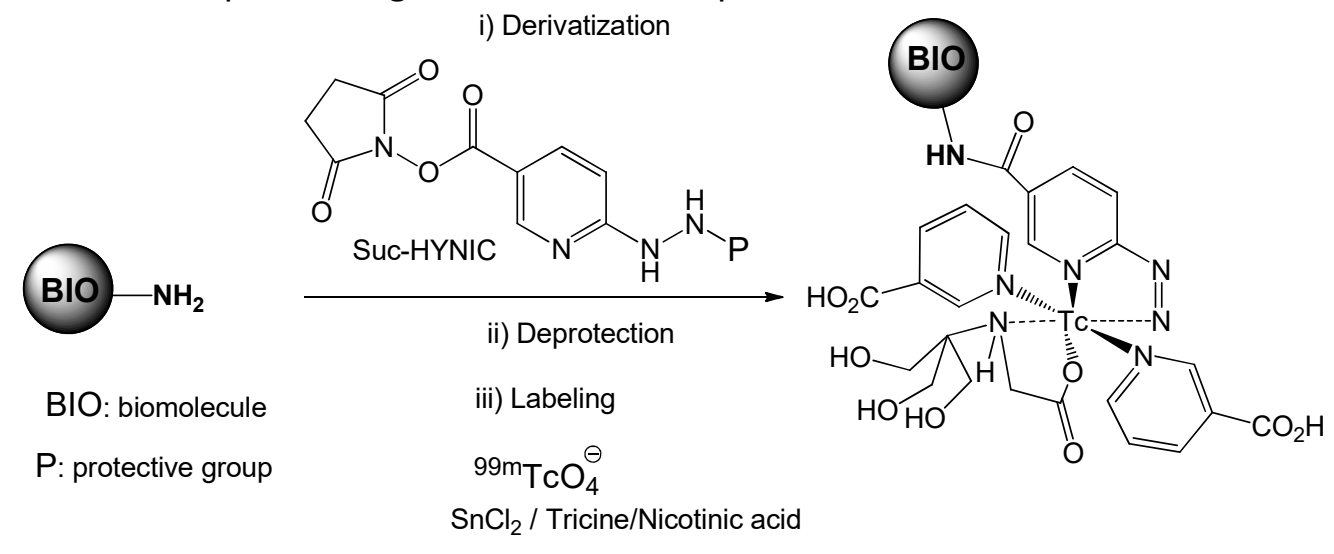

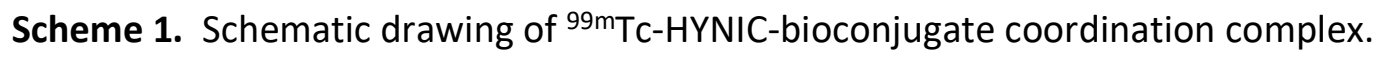

In order to prevent the degradation of the conjugate, different HYNIC derivatives were developed with the suitably protected hydrazino group. In this context, we have recently developed for the first time to our knowledge, a microwave-assisted organic synthesis methodology to obtain HYNIC derivatives protected with Boc and TFA group. ${ }^{4}$ Many recent scientific articles describe the use of microwave irradiation in organic synthesis as a great advantage over electric heating plates or oil baths due to the short reaction times required and to the simplicity of the equipment. ${ }^{5,6}$ In addition, solid-phase organic synthesis allows chemical transformations using polymer-bound reagents. ${ }^{7,8}$ The procedures of solid-phase synthesis greatly simplify the isolation and purification of the reaction product by simple filtration and by washing out with suitable solvents all excess reagents and byproducts that have not bound to the solid support. 
In the last years, microwave-assisted solid-phase synthesis (MASS), a combination of solid-phase synthesis and microwave irradiation, has contributed significantly to the development of new and efficient synthetic processes. ${ }^{9,10}$ In this context, our group is interested in developing a method for rapid synthesis of Suc-HYNIC analogue by MASS methodology. As part of our ongoing investigations in the development of new ${ }^{99 \mathrm{~m}} \mathrm{Tc}$ radiopharmaceuticals, we set out to design a new and convenient method for synthesis of Suc-HYNIChydrazone under MASS conditions, with the aim of increasing yields and shortening reaction times. During the formation of the HYNIC-bioconjugate, hydrazones were conjugated efficiently in anhydrous medium. Subsequently, when labeling with ${ }^{99 \mathrm{~m}} \mathrm{Tc}$, the deprotection occurred in one step (Scheme 1). ${ }^{11,12}$ Here, we present the synthesis of SUC-HYNIC hydrazone and its derivatization through MASS methodology.

\section{Results and Discussion}

The route designed to obtain Suc-HYNIC-hydrazone through microwave-assisted solid-phase synthesis is shown in Scheme 2. A supported-aldehyde is proposed as starting material. A first step of HYNIC immobilization, followed by activation of the carboxylic acid functionality and cleavage of the resin, could generate the desired product. In addition, we propose to study a derivatization strategy by solid-phase synthesis in order to obtain a hydrazone-HYNIC-bioconjugate. To obtain the supported aldehyde, commercial Wang resin was used or synthesized in our laboratory from Merrifield resin according to the procedure of Yang et al. (Scheme 3) with modifications. ${ }^{13,14}$ Initially, 4-hydroxybenzaldehyde was immobilized to Merrifield resin under microwave heating (multimode reactor) at $100 \mathrm{~W}$ for 10 minutes using DMF as solvent. Under these conditions, complete conversion was achieved as judged by on-bead FTIR. This resulted in the appearance of new bands at 1686 and $1593 \mathrm{~cm}^{-1}$, all corresponding to the stretching vibration of the $\mathrm{C}=\mathrm{O}$ bond. We also have performed this transformation under conventional conditions ( $\mathrm{NaH}$ as base, r.t. for $24 \mathrm{~h}$ ) with identical results.

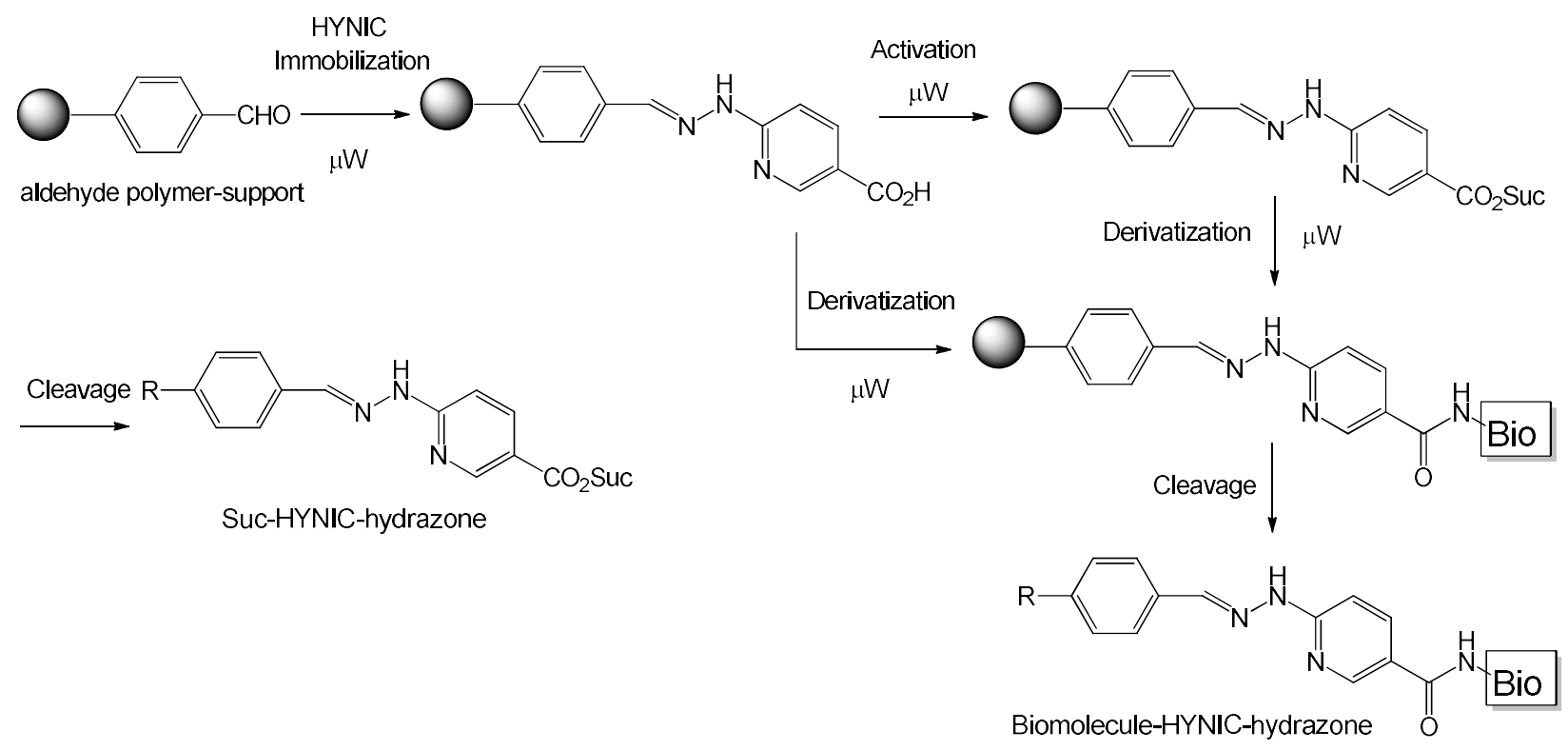

Scheme 2. Synthetic route designed for Suc-HYNIC-hidrazone and HYNIC-bioconjugate through MASS methodology. 
The Wang resin was obtained by reduction of the aldehyde group with $\mathrm{NaBH}_{4}$ in presence of $\mathrm{NMM}$. Progress of carbonyl reduction was followed using on-bead FTIR spectroscopy to observe the disappearance of the characteristic aldehyde group and the presence of characteristic $\mathrm{OH}$ vibrations at 3430 and $1609 \mathrm{~cm}^{-1}$. Wang resin treated with 4-hydroxybenzaldehyde under Mitsunobu condition ( 2 cycles) using THF as solvent afforded aldehyde resin 1 in good yield (Scheme 3). The conversion of the resin at this step (as well as at the first step of Wang resin synthesis) was monitored using the Brady color test for aldehydes. ${ }^{15}$ The loading of resin 1 was verified after cleavage with $50 \% \mathrm{TFA} / \mathrm{CH}_{2} \mathrm{Cl}_{2}$ at room temperature for $1 \mathrm{~h}(70 \%$ overall yield, $1.05 \mathrm{mmol} / \mathrm{g})$.
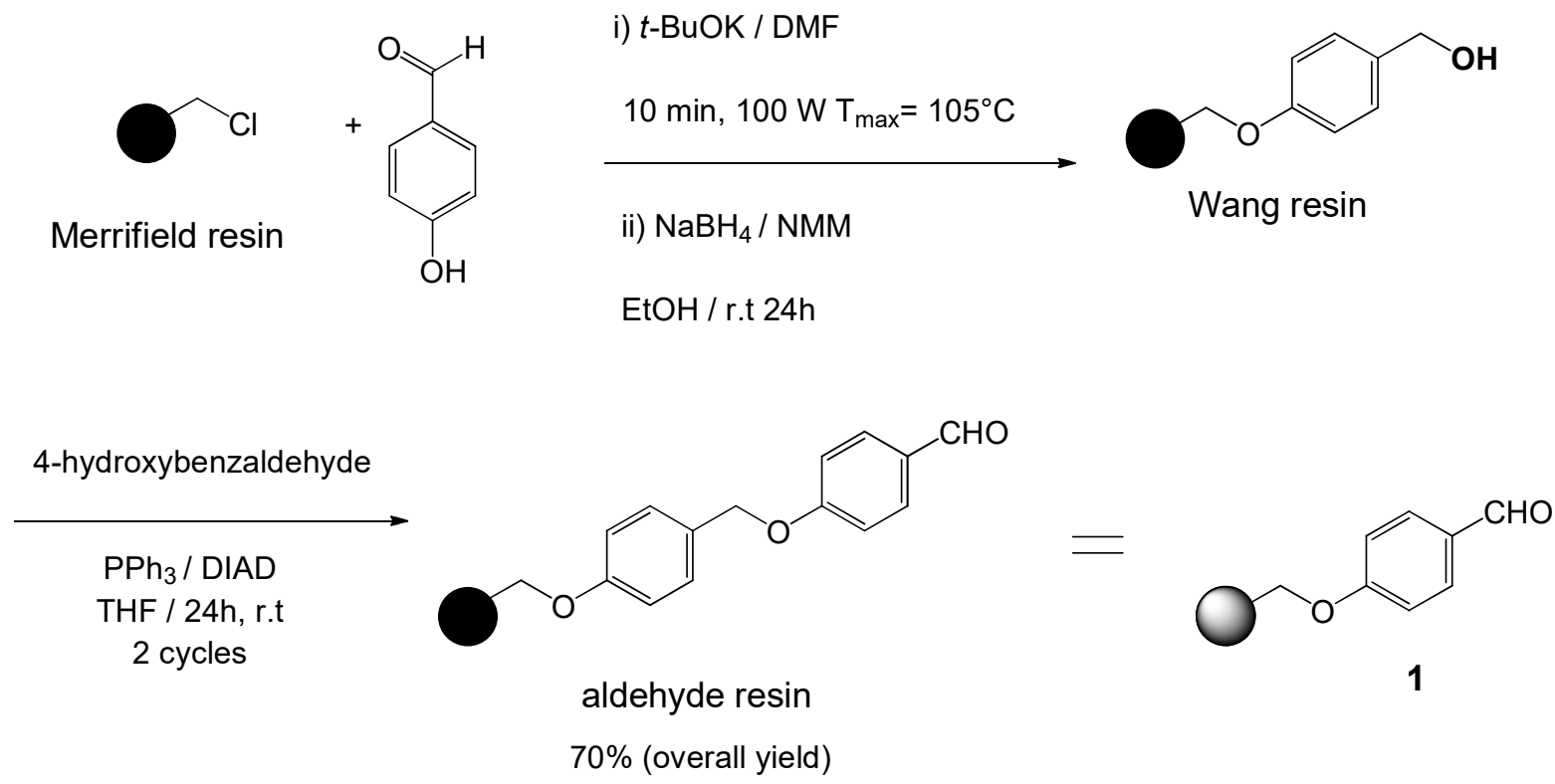

Scheme 3. Solid-phase synthesis of aldehyde resin.

Quantitative yields were obtained for HYNIC-hydrazone $\mathbf{2}$ when polymer-supported aldehyde $\mathbf{1}$ and HYNIC (6-hydrazinonicotinic acid) were irradiated in a closed vessel after $10 \mathrm{~min}$ at $100{ }^{\circ} \mathrm{C}$, using $p$-toluenesulfonic acid as catalyst (Scheme 4). The condensation reaction gave the corresponding supported HYNIC-hydrazone with purity and yield greater than $95 \%$ and $98 \%$, respectively, as judged by ${ }^{1} \mathrm{H}-\mathrm{NMR}$ analysis of the cleaved compound 4. When we performed this transformation under conventional heating $\left(100^{\circ} \mathrm{C}, 12 \mathrm{~h}\right)$, the aldehyde resin was obtained in moderate yield ( $90 \%$ purity, $60 \%$ yield). These results revealed an accelerating effect on the condensation reaction with the use of microwaves.

Subsequently, the supported activated ester 3 (Suc-HYNIC-hydrazone resin, Scheme 4) was obtained from the corresponding acid 2 and NHS in the presence of DCC by microwave heating $\left(80^{\circ} \mathrm{C}, 10 \mathrm{~min}\right)$. Cleavage from the solid support was performed using $50 \%$ TFA in $\mathrm{CH}_{2} \mathrm{Cl}_{2}$, with a Suc-HYNIC-hydrazone 5 overall average yield of $84 \%$ (Scheme 4). Longer reaction times $(30 \mathrm{~min}$ ) under microwave irradiation did not increase the conversion rate, whereas higher temperature $\left(100^{\circ} \mathrm{C}\right)$ promoted the hydrolysis reaction. When we performed the esterification reaction at room temperature for $24 \mathrm{~h}$, hydrazone 5 was obtained in moderate yield $(39 \%$ overall yield). When the activation reaction was conducted under conventional thermal heating for $8 \mathrm{~h}$ at 80 ${ }^{\circ} \mathrm{C}$, approximately $70 \%$ overall yield was obtained. Therefore, microwave irradiation significantly accelerated the formation of the activated HYNIC-hydrazone system. 


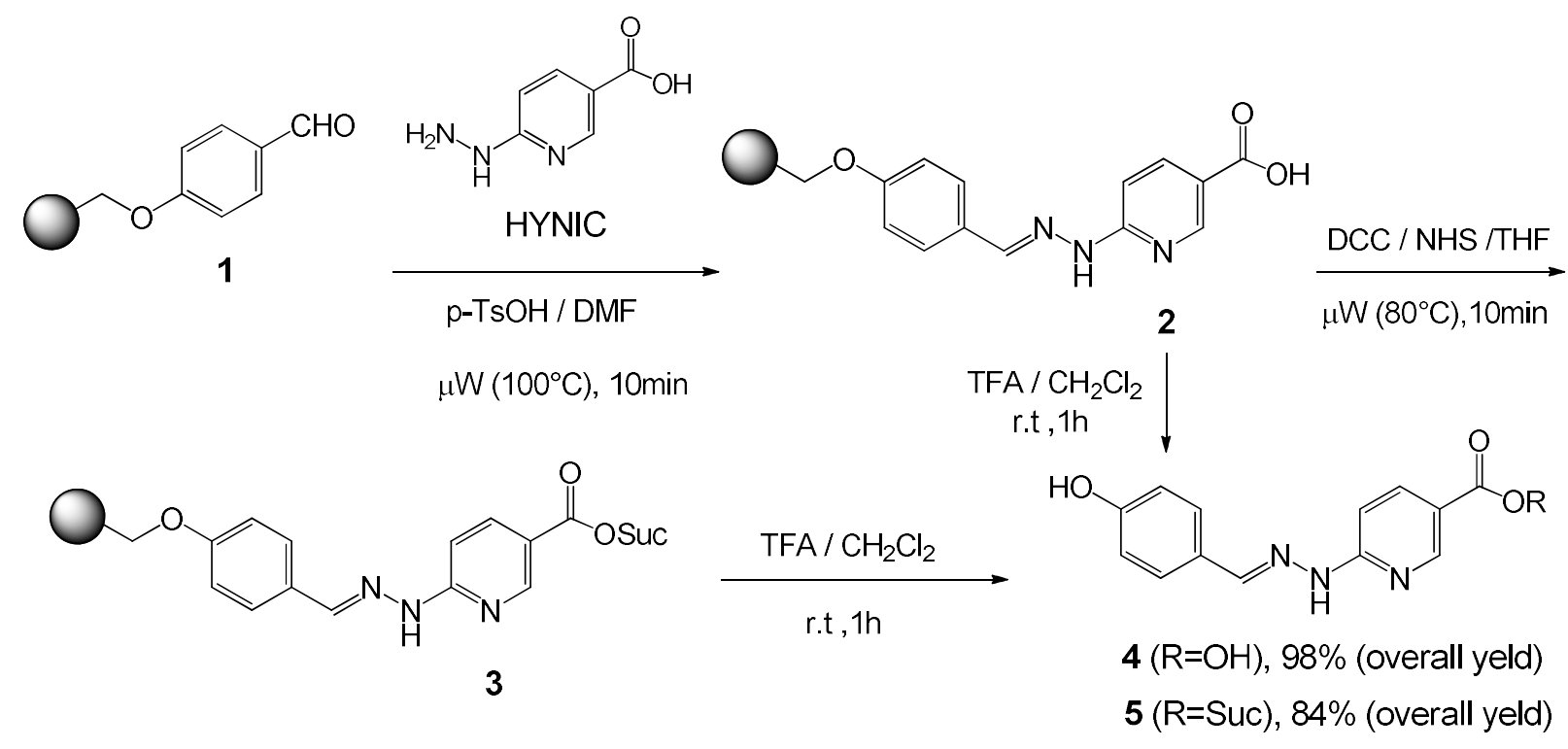

Scheme 4. Synthesis of Suc-HYNIC-hydrazone through MASS methodology.

Furthermore, we decided to explore obtaining a HYNIC-bioconjugate using the present methodology and a primary fatty amine, stearylamine, as model of reactivity. Therefore, we conducted the synthesis of $\mathrm{N}$ stearylamide-HYNIC-hydrazone $\mathbf{7}$ through MASS methodology. The supported carboxylic acid $\mathbf{2}$ was used to synthesize the corresponding stearylamide by solid-phase synthesis, using HBTU as activating agent, and HOBt and DIPEA as additive and base, respectively (Scheme 5). Initially, when the reaction was conducted under conventional conditions at room temperature for $24 \mathrm{~h}$, the corresponding stearylamide 7 was obtained in moderate overall yield after resin cleavage (condition a, 60\%, Scheme 5). By applying microwave irradiation $\left(10 \mathrm{~min}\right.$ at $\left.80^{\circ} \mathrm{C}\right)$, we were able to significantly shorten the reaction time and to obtain the product of interest in high yield and purity (condition b, 89\%, Scheme 5). In this case, an increase in the microwave exposure time (from 10 to $20 \mathrm{~min}$ ) or the temperature (from $80^{\circ} \mathrm{C}$ to $100{ }^{\circ} \mathrm{C}$ ) did not correlate with an increase in the conversion rate. We also evaluated an alternative route to obtain the stearylamide 7 , through the reaction between the activated supported ester 3 and stearylamine. First, the reaction was assayed in $\mathrm{DMSO} / \mathrm{CHCl}_{3}(\mathrm{a}$ suitable mixture for solubilizing sterylamine) at room temperature for $24 \mathrm{~h}$ (condition $\mathrm{c}$, Scheme 5 ). We obtained the desired product in good overall yield and high purity ( $79 \%$ and $95 \%$, respectively). Considering that the reaction required extensive time, we assayed microwave heating to accelerate the transformation. As expected, when the reaction was conducted under microwave heating at $60^{\circ} \mathrm{C}$ for $10 \mathrm{~min}$, similar results were obtained (condition d, Scheme 5).

Finally, typical radiolabeling conditions for HYNIC conjugates were tested on HYNIC-hydrazone 4 as a model of chemical reactivity using tricine and nicotinic acid as coligands ( $\mathrm{pH} 4-5$ at $70^{\circ} \mathrm{C}$ for $1 \mathrm{~h}$ ). The HPLC results show one peak at 7.36 min corresponding to radiolabeled HYNIC (HYNIC- ${ }^{99 m}$ Tc complexes) with radiochemical purity over $99 \%$ and a radiochemical yield over $80 \%$ (Figure 1). The UV peak appears at 7.38 min with a purity over $88 \%$. Similar results were obtained when HYNIC was labeled under the same conditions (data not shown). This confirms that the 4-hydroxybenzaldehyde group was removed during labeling, forming

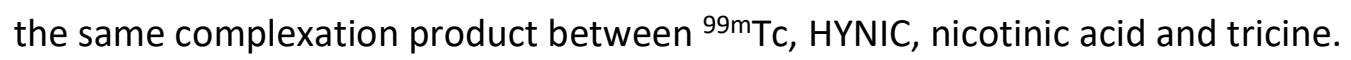




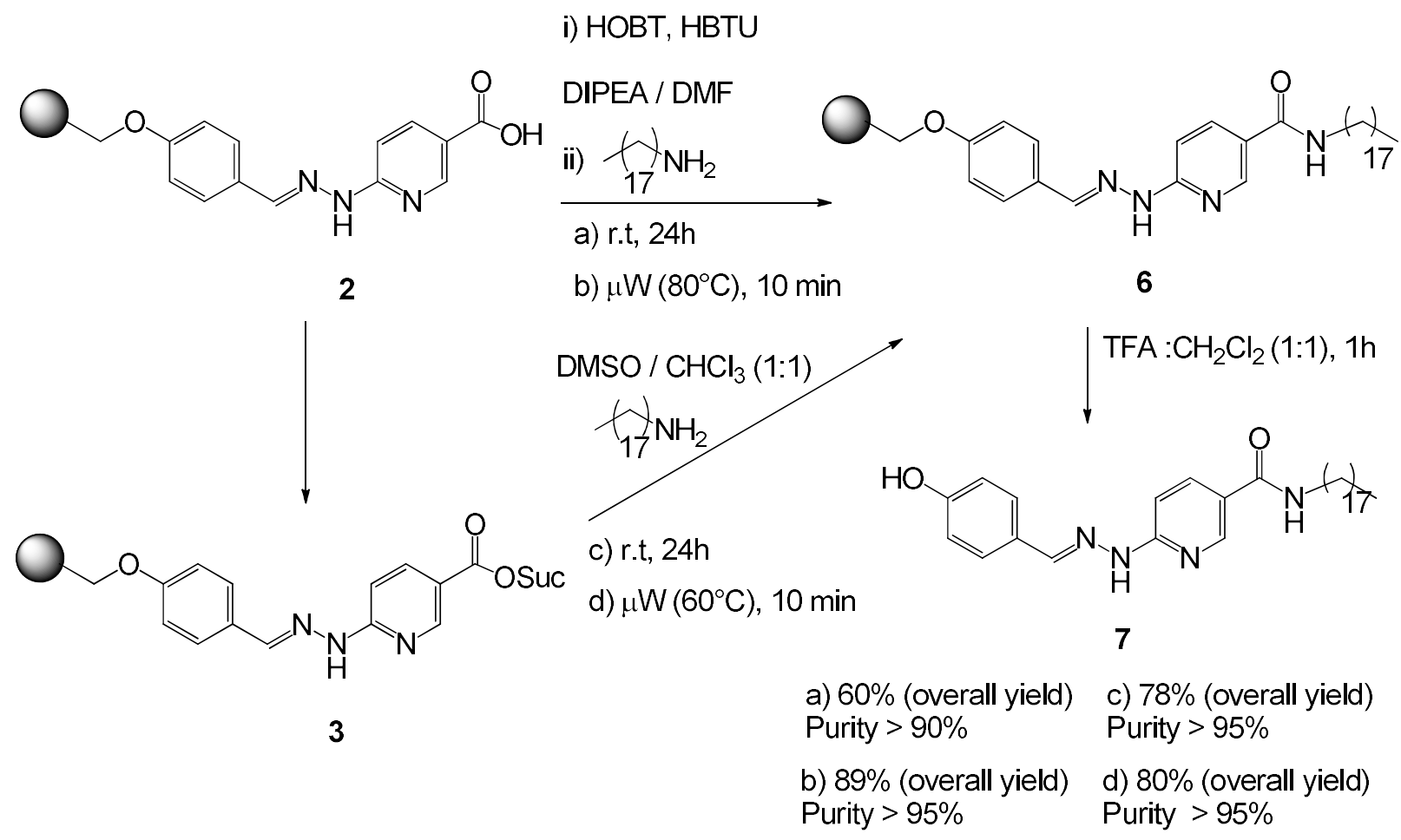

Scheme 5. Solid-phase synthesis of stearylamide-HYNIC-hydrazone 7.

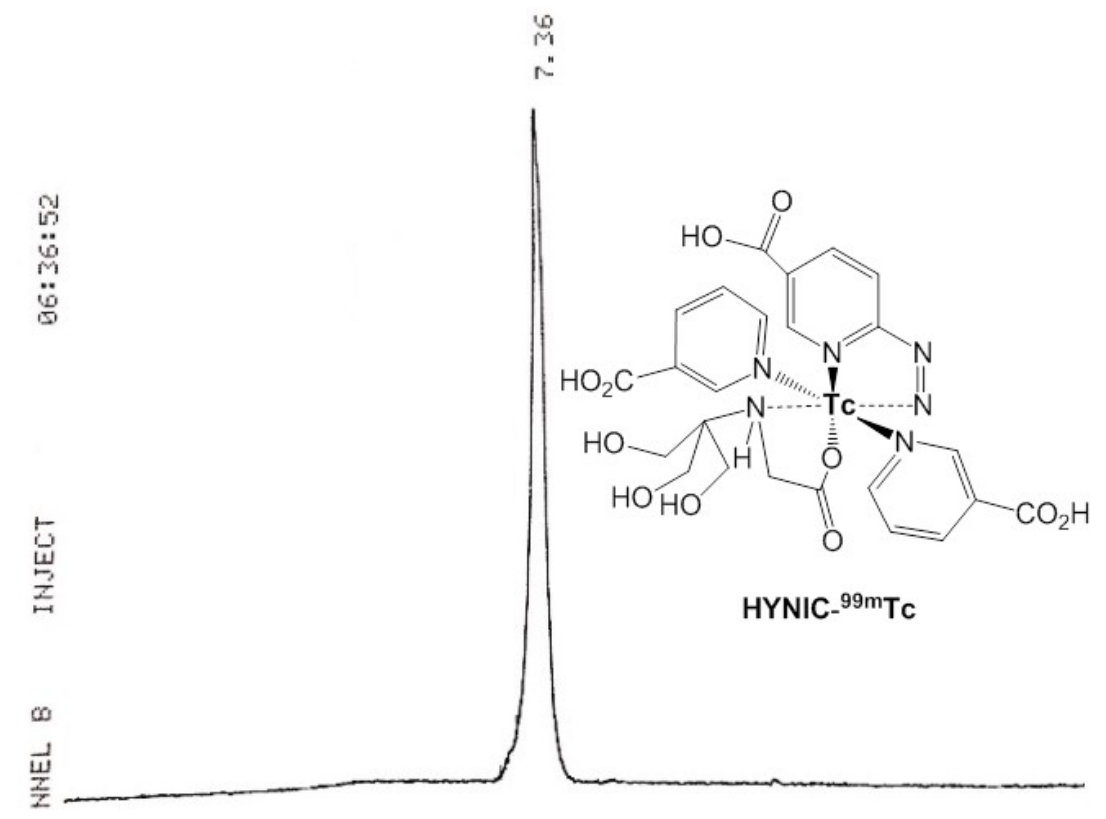

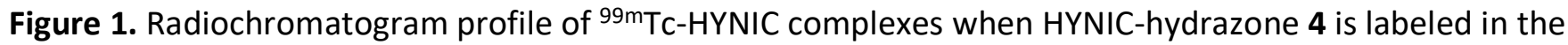
presence of stannous chloride, tricine and nicotinic acid. 


\section{Conclusions}

In the present work, we have developed an efficient and rapid solid-phase and microwave-assisted approach for the synthesis of HYNIC-hydrazone derivatives. All steps were monitored by cleavage of resin aliquots, followed by ${ }^{1} \mathrm{H}$ NMR and mass spectrometry of the products. Extension of this methodology is currently ongoing in our laboratory to include more elaborated substrates. We showed that the bifunctional ligand HYNIC, suitably protected by a hydrazone moiety, can be labeled directly with technetium without exposing the free hydrazine group. Therefore, we have developed a useful synthetic methodology for the preparation of HYNIC bioconjugates with potential application in ${ }^{99 \mathrm{~m} T c}$ radiochemistry.

\section{Experimental Section}

General. All solvents were distilled prior to use. Analytical TLC was performed on silica gel $60 \mathrm{~F}-254$ plates and visualized with UV light ( $254 \mathrm{~nm})$ and/or anisaldehyde in acidic ethanolic solution. Column chromatography was performed using silica gel (SAI, 63-200 nm). Melting points were determined with a melting point apparatus (Electrothermal 9100). Proton and carbon NMR spectra were recorded on a Bruker DPX-400 spectrometer. The chemical shifts values are expressed in ppm relative to tetramethylsilane as internal standard. High-resolution mass spectra were performed on a BrukerDaltonics spectrometer model MicrOTofQ (ESI+mode). Structural assignments are based on ${ }^{1} \mathrm{H},{ }^{13} \mathrm{C}, \mathrm{COSY}, \mathrm{HMBC}, \mathrm{HMQC}$, and MS spectroscopies. Microwave experiments: reactions in sealed vessels were conducted in commercial microwave systems, multimode cavity WX-4000 from EU Chemical Instrument Co, with a microwave power delivery system ranging from $100 \mathrm{~W}$ to $1000 \mathrm{~W}$. Experiments were carried out in closed $60 \mathrm{~mL}$ reactors made of Teflon ${ }^{\mathrm{TM}}$. The temperature was monitored via a fiberoptic contact thermometer protected in a Teflon-coated, inserted directly into the reaction mixture. The vessel contents were stirred by means of an adjustable rotating magnetic plate located below the floor of the microwave cavity. Temperature, pressure, and power profiles were monitored using commercially available software provided by the manufacturers. Infrared spectra (IR) were obtained using a Shimadzu IR equipment Affinity-1 (Fourier Transform Infrared Spectrophotometer).

Preparation of Wang resin. Merrifield resin (1g, $3.0 \mathrm{mmol} / \mathrm{g}, 100-200 \mathrm{mesh}, 1 \%$ cross-linked) was placed in a $60 \mathrm{~mL}$ Teflon reactor and swelled with $15 \mathrm{~mL}$ DMF for $10 \mathrm{~min}$. Then, sodium tert-buthoxide (2 equiv) and $p$ hydroxybenzaldehyde ( 2 equiv) dissolved in $5 \mathrm{~mL} \mathrm{DMF}$ were subsequently mixed with the swelled resin. The mixture was then heating under microwave irradiation in a sealed tube at $100 \mathrm{~W}\left(\mathrm{~T}_{\max }=105^{\circ} \mathrm{C}\right)$ for $10 \mathrm{~min}$. After cooling at room temperature, the suspension was filtered and washed three times with $\mathrm{H}_{2} \mathrm{O}(15 \mathrm{~mL})$, $\mathrm{MeOH}(15 \mathrm{~mL}), \mathrm{DCM}(15 \mathrm{~mL})$, and diethyl ether $(15 \mathrm{~mL})$. The resin was finally dried in vacuo at $25^{\circ} \mathrm{C}$ for $24 \mathrm{~h}$. FTIR (neat): $1683,1593,1348$, and $1181 \mathrm{~cm}^{-1}$. Finally, a suspension of resin (1 equiv), $\mathrm{NaBH}_{4}(2$ equiv) and NMM (10 equiv) in EtOH ( $1.5 \mathrm{~mL} / 100 \mathrm{mg}$ resin) was added to preswollen resin, and the slurry was shaken for $24 \mathrm{~h}$ at room temperature. The resin was washed with water, $\mathrm{MeOH}, \mathrm{DCM}$ and diethyl ether. The resulting resin was dried in vacuo to provide Wang resin. FTIR (neat): 3430, 1609, 1348, and $1181 \mathrm{~cm}^{-1}$.

Preparation of aldehyde resin (1). Wang resin (100 mg; loading, $1 \mathrm{mmol} / \mathrm{g}$ ) was swollen in $2 \mathrm{~mL}$ of THF for 15 min. $p$-Hydroxybenzaldehyde $(96 \mathrm{mg}, 0.23 \mathrm{mmol}$ ) and triphenylphosphine $(72 \mathrm{mg}, 0.27 \mathrm{mmol})$ were dissolved in $2 \mathrm{~mL}$ of THF and added to the swollen resin. A $42 \mu \mathrm{L}(0.27 \mathrm{mmol})$ portion of DEAD was diluted to $200 \mu \mathrm{L}$ with THF and added dropwise to the mixture at room temperature. The reaction was run overnight. The 
mixture was then removed, and the resin was washed sequentially with dichloromethane $(3 \times)$, DMF $(3 \times)$, methanol $(2 \times)$, DMF $(2 \times)$, and finally diethyl ether, and then dried in vacuo. The substitution level of the loaded aldehyde resin, determined after cleavage with $50 \%$ TFA $/ \mathrm{CH}_{2} \mathrm{Cl}_{2}$ at room temperature for 1, was 0.9 $\mathrm{mmol} / \mathrm{g}$.

HYNIC-hydrazone resin (2). A Teflon tube was charged sequentially with aldehyde resin 1 (650 mg), DMF (8 $\mathrm{mL}$ ), HYNIC (5 equiv), and $p-\mathrm{TsOH}$ (0.1 equiv). The reactor tube was sealed with Teflon septum and placed inside the cavity of the microwave reactor, operated at $80^{\circ} \mathrm{C}$ for $10 \mathrm{~min}$. After cooling at room temperature, the suspension was filtered and washed three times with $\mathrm{H}_{2} \mathrm{O}(15 \mathrm{~mL}), \mathrm{MeOH}(15 \mathrm{~mL}), \mathrm{DCM}(15 \mathrm{~mL})$, and diethyl ether $(15 \mathrm{~mL})$. The resin 2 was finally dried in vacuo at $25^{\circ} \mathrm{C}$ for $24 \mathrm{~h}$. FTIR (neat): 3430, 1609, 1348, and $1181 \mathrm{~cm}^{-1}$.

Cleavage: a suspension of resin 2 (100 mg) in a freshly prepared solution of 50\% TFA in DCM (1-5 mL) was shaken for $1 \mathrm{~h}$ at room temperature. The resin was washed with DCM and the organic solvent concentrated to give the crude product. After workup, the residue was purified by column chromatography $\left(\mathrm{SiO}_{2}\right.$, mixtures of petroleum ether:EtOAc).

6-((4-Hydroxybenzylidene)hydrazinyl)nicotinic acid (4). Brown solid, mp 272-274 ${ }^{\circ} \mathrm{C} .{ }^{1} \mathrm{H}$ NMR (MeOD- $\left.d_{4}\right) \delta$ (ppm): 6.89 (d, J $8.8 \mathrm{~Hz}, 2 \mathrm{H}), 7.19$ (d, J $9.2 \mathrm{~Hz}, 1 \mathrm{H}), 7.80$ (d, J $8.4 \mathrm{~Hz}, 2 \mathrm{H}), 8.22(\mathrm{~s}, 1 \mathrm{H}), 8.41$ (dd, J $2.0 \mathrm{~Hz}, J 9.6$

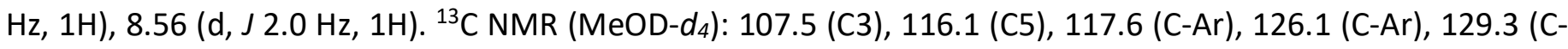
Ar), 138.7 (C4), 143.8 (C=N), 152.9 (C6), 155.7 (C2), 159.2 (C-Ar-OH), 160.8 (C=O) ESI-MS, m/z: 258,0877 [M+H] and $280,0693 \mathrm{~m} / \mathrm{z}[\mathrm{M}+\mathrm{Na}]$.

Suc-HYNIC-hydrazone resin (3): A Teflon tube was charged sequentially with HYNIC-hydrazone resin 2 (1.3 g), TFH (15 mL), DCC (5 equiv) and NHS (5 equiv). The test tube was then sealed with Teflon septum and heated for $10 \mathrm{~min}$ at $80^{\circ} \mathrm{C}$ by microwave irradiation. The vial was cooled, and the crude reaction mixture was filtered and washed three times with DMF $(15 \mathrm{~mL})$, dichloromethane $(15 \mathrm{~mL})$, and diethyl ether $(15 \mathrm{~mL})$. The resin was finally dried in vacuo at $25^{\circ} \mathrm{C}$ for $24 \mathrm{~h}$.

Cleavage: identical to the previously used method.

Succinimidyl 6-((4-Hydroxybenzylidene)hydrazinyl)nicotinic acid (5). Brown solid, mp 200-203 ${ }^{\circ} \mathrm{C} .{ }^{1} \mathrm{H}$ NMR (DMSO-d $d_{6} \delta(\mathrm{ppm}): 2.88(\mathrm{~s}, 4 \mathrm{H}), 6.82(\mathrm{~d}, J 8.4 \mathrm{~Hz}, 2 \mathrm{H}), 7.30(\mathrm{~d}, J 8.8 \mathrm{~Hz}, 1 \mathrm{H}), 7.57(\mathrm{~d}, J 8.0 \mathrm{~Hz}, 2 \mathrm{H}), 8.11(\mathrm{~s}, 1 \mathrm{H})$, 8.15 (dd, J 2.4, J $9.2 \mathrm{~Hz}, 1 \mathrm{H}$ ), $8.78(\mathrm{~d}, J 2.0 \mathrm{~Hz}, 1 \mathrm{H}), 11.60$ (bs, $1 \mathrm{H}) .{ }^{13} \mathrm{C} \mathrm{NMR}$ (DMSO-d $) \delta(\mathrm{ppm}): 26.1\left(\mathrm{CH}_{2}\right)$, 106.9 (C3), 116.5 (C5), 117.2 (C-Ar), 126.5 (C-Ar), 129.8 (C-Ar), 139.8 (C4), 144.5 (C=N), 152.1 (C6), 156.3 (C2), 159.9 (C-Ar-OH), 160.2 (O-C=O), 170.8 (N-C=O) ESI-MS, m/z: $554.0942\left(\mathrm{M}^{+}\right)$.

Stearylamide-HYNIC-hydrazone resin (6).

Condition b): HYNIC-hydrazone resin $(1 \mathrm{~g}, 3.0 \mathrm{mmol} / \mathrm{g})$ was placed in a $60 \mathrm{~mL}$ Teflon reactor and swelled with $15 \mathrm{~mL}$ DMF for $10 \mathrm{~min}$. A mixture of HBTU (1 equiv), HOBT (1 equiv) and DIPEA (2 equiv) in anhydrous DMF $(5 \mathrm{~mL}$ ) was then added and agitated at room temperature for $1 \mathrm{~h}$. Stearylamine (5 equiv) was then added to the reaction mixture and heated for $10 \mathrm{~min}$ at $80^{\circ} \mathrm{C}$ by microwave irradiation. After cooling at room temperature, the suspension was filtered and washed three times with $\mathrm{MeOH}(15 \mathrm{~mL}), \mathrm{DCM}(15 \mathrm{~mL})$, and diethyl ether $(15 \mathrm{~mL})$. The resin was finally dried in vacuo at $25^{\circ} \mathrm{C}$ for $24 \mathrm{~h}$.

Cleavage: identical to the previously used method.

Stearyl 6-((4-Hydroxybenzylidene)hydrazinyl)nicotinicamide (7). Brown solid, mp 132-134 ${ }^{\circ} \mathrm{C} .{ }^{1} \mathrm{H}$ NMR (Acetone- $\left.d_{6}\right) \delta(\mathrm{ppm}): 0.86(\mathrm{t}, J 6.4 \mathrm{~Hz}, 3 \mathrm{H}), 1.29(\mathrm{bs}, 30 \mathrm{H}), 1.59(\mathrm{~m}, 2 \mathrm{H}), 3.39(\mathrm{t}, J 6.8 \mathrm{~Hz}, 2 \mathrm{H}), 6.93(\mathrm{~d}, J 8.4 \mathrm{~Hz}$, $2 \mathrm{H}), 7.68(\mathrm{~d}, J 8.4 \mathrm{~Hz}, 1 \mathrm{H}), 7.73(\mathrm{~d}, J 8.4 \mathrm{~Hz}, 2 \mathrm{H}), 7.97(\mathrm{bs}, 1 \mathrm{H}), 8.27(\mathrm{~s}, 1 \mathrm{H}), 8.44$ (dd, J $1.2 \mathrm{~Hz}, J 9.2 \mathrm{~Hz}, 1 \mathrm{H}), 8.60$ (s, $1 \mathrm{H}) .{ }^{13} \mathrm{C}$ NMR (Acetone- $\left.d_{6}\right): \delta 13.5\left(\mathrm{CH}_{3}\right), 24.2\left(\mathrm{CH}_{2}\right), 29.1\left(\mathrm{CH}_{2}\right), 35.6\left(\mathrm{CH}_{2}-\mathrm{CH}_{2}-\mathrm{N}\right), 47.3\left(\mathrm{CH}_{2}-\mathrm{N}\right), 111.5(\mathrm{C} 3)$, 121.8 (C5), 124.2 (C-Ar), 128.5 (C-Ar), 130.1 (C-Ar), 131.8 (C-Ar), 132.4 (C4), 139.8 (C6), 142.4 (C=N), 154.1 (C2), $168.2(\mathrm{~N}-\mathrm{C}=\mathrm{O})$ ESI-MS, m/z: $509.3851\left(\mathrm{M}^{+}+\mathrm{H}\right)$. 
Condition d): A Teflon tube was charged sequentially with Suc-HYNIC-hydrazone resin (650 mg), $\mathrm{DMSO} / \mathrm{CHCl}_{3}$ $(1: 1,8 \mathrm{~mL})$, and sterylamine ( 2 equiv). The reactor tube was sealed with Teflon septum and placed inside the cavity of the microwave reactor, operated at $60^{\circ} \mathrm{C}$ for $10 \mathrm{~min}$. After cooling at room temperature, the suspension was filtered and washed three times with $\mathrm{H}_{2} \mathrm{O}(15 \mathrm{~mL}), \mathrm{MeOH}(15 \mathrm{~mL}), \mathrm{DCM}(15 \mathrm{~mL})$, and diethyl ether $(15 \mathrm{~mL})$. The HYNIC-hydrazone resin was finally dried in vacuo at $25^{\circ} \mathrm{C}$ for $24 \mathrm{~h}$.

\section{Radiosynthesis}

Water was purified and deionized $\left(18 \mathrm{M} \Omega / \mathrm{cm}^{2}\right)$ via a Milli-Q water filtration system (Millipore Corp., Milford, MA). ${ }^{99} \mathrm{Mo-}{ }^{99 \mathrm{~m} T c}$ generators were purchased from TecnoNuclear (Argentina). High performance liquid chromatography (HPLC) was performed on an HPLC Varian 5000 Liquid Chromatograph, integrator 4290 Varian, simultaneous detection by $\mathrm{Nal}$ (TI) crystal detector (ORTEC)) and UV detector ( $\lambda=254 \mathrm{~nm}$ ), Column Thermo Scientific Hypersil ODS (C18) $(300 \mathrm{~mm} \times 4.6 \times 10 \mu \mathrm{m})$. The flow rate was $1 \mathrm{~mL} / \mathrm{min}$ used with a gradient mobile phase from $100 \%$ of $A\left(0.1 \%\right.$ TFA in $\left.\mathrm{H}_{2} \mathrm{O}\right)$ to $100 \%$ of $B(0.1 \%$ TFA in acetonitrile) in 20 min. Labeling conditions: $1 \mathrm{~mL}$ of HYNIC-hydrazone in DMSO $(1 \mathrm{mg} / \mathrm{mL})$ was incubated with $0.4 \mathrm{~mL}$ of tricine solution (100 $\mathrm{mg} / \mathrm{mL}$ in water), $0.2 \mathrm{~mL}$ nicotinic acid solution $\left(10 \mathrm{mg} / \mathrm{ml}\right.$ in water), $100 \mu \mathrm{L}$ of ${ }^{99 \mathrm{~m} \mathrm{TcO}_{4}}{ }^{-}(37-111 \mathrm{MBq})$ and 15 $\mu \mathrm{L}$ of $\mathrm{SnCl}_{2} .2 \mathrm{H}_{2} \mathrm{O}(1 \mathrm{mg} / \mathrm{mL}$ in nitrogen-purged $0.1 \mathrm{M} \mathrm{HCl})$ for $60 \mathrm{~min}$ at $70{ }^{\circ} \mathrm{C}$ tofinal $\mathrm{pH}$. The reaction was analyzed for radiochemical purity by HPLC. CPS: counts per second.

\section{Acknowledgements}

This work was supported by PEDECIBA-Química, Comisión Sectorial de Investigación Científica (CSIC)-UdelaR (CSIC-N ${ }^{\circ} 417$ ) and Espacio Interdisciplinario, UdelaR (Grupo Oncología Nuclear). We thank Agencia Nacional de Investigación e Innovación (ANII) for scholarship to VT.

\section{Abbreviations}

Boc: tert-Butyloxycarbonyl group

DCC: Dicyclohexyl carbodiimide

DEAD: Diethyl azodicarboxylate

DIPEA: $N, N$-Diisopropylethylamine

DMF: Dimethylformamide

HBTU: 2-(1H-benzotriazole-1-yl)-1,1,3,3-tetramethyluronium hexafluorophosphate

HOBt: 1-Hydroxybenzotriazole

HYNIC: 6-Hydrazinonicotinic acid

MASS: Microwave-assisted solid-phase synthesis

NMM: N-Methylmorpholine

NHS: $N$-Hydroxysuccinimide

Suc: Succinimidyl group

Tricine: [(tris(Hydroxymethyl)methyl]glycine 


\section{References}

1. Liu, S. Chem. Soc. Rev. 2004, 33, 445.

https://doi.org/10.1039/b309961j

2. Jurisson, S.; Berning, D.; Jia, W; Ma, O. Chem. Rev. 1993, 93, 1137.

https://doi.org/10.1021/cr00019a013

3. Meszaros, L. K.; Dose, A.; Biagini, S. C. G.; Blower, P.J. Inorg. Chim. Acta 2010, 363, 1059. https://doi.org/10.1016/i.ica.2010.01.009

4. García, M. F.; Calzada, V.; Camacho, X.; Goicochea, E.; Gambini, J. P.; Quinn, T. P.; Porcal, W.; Cabral, P. Curr. Radiopharm. 2014, 7, 84. https://doi.org/10.2174/1874471007666141128160449

5. $\quad$ Mert-Balci, F.; Conrad, J.; Beifuss, U. Arkivoc 2012 (iii), 243. http://dx.doi.org/10.3998/ark.5550190.0013.318

6. Jordan, C.A.; Wieczerzak, K.B.; Knisley, K.J.; Ketcha, D.M. Arkivoc 2014 (iv), 183. http://dx.doi.org/10.3998/ark.5550190.p008.205

7. Feliu, L.; Font, D.; Soley, R.; Tailhades, J.; Martinez, J.; Amblard, M. Arkivoc 2007 (iv), 65. http://dx.doi.org/10.3998/ark.5550190.0008.406

8. Ermolat'ev, D.S.; Babaev, E.V. Arkivoc 2005 (iv), 172. http://dx.doi.org/10.3998/ark.5550190.0006.413

9. Ríos, N.; Varela, J.; Birriel, E.; González, M.; Cerecetto, H.; Merlino, A.; Porcal, W. Fut. Med. Chem. 2013, $5,1719$. https://doi.org/10.4155/fmc.13.160

10. Pedersen, S.L.; Pernille Tofteng, A.; Malika, L.; Jensen, K.J. Chem. Soc. Rev. 2012, 41, 1826. https://doi.org/10.1039/C1CS15214A

11. Gandomkar, M.; Najafi, R.; Shafiei, M.; Ebrahimi, S.E. Appl. Radiat. Isot. 2007, 65, 805. https://doi.org/10.1016/i.apradiso.2007.03.002

12. Harris, T.D.; Sworin, M.; Williams, N.; Rajopadhye, M.; Damphousse, P.R.; Glowacka, D.; Poirier, M.J.; Yu, K. Bioconjugate Chem. 1999, 10, 808. https://doi.org/10.1021/bc9900237

13. Al-Obeidi, F.; Austin, R.E.; Okonya, J.F.; Bond, D.R.S. Mini Rev. Med. Chem. 2003, 3, 449. https://doi.org/10.2174/1389557033488042

14. Yang, H.; Peng, Y.; Song, G.; Qian, X. Tetrahedron Letters 2001, 42, 9043. https://doi.org/10.1016/S0040-4039(01)02003-2

15. Shannon, S.K.; Barany, G. J. Comb. Chem. 2004, 6, 165. https://doi.org/10.1021/cc034033x 